\title{
A comprehensive spectroscopic, solvatochromic and photochemical analysis of 5-hydroxyquinoline and 8-hydroxyquinoline mono-azo dyes
}

\author{
Hamid Rashidnejad ${ }^{a}$, Mohammad Ramezanitaghartapeh ${ }^{\mathrm{b}, * *}$, Nader Noroozi Pesyan ${ }^{\mathrm{a}}$, \\ Peter J. Mahon ${ }^{b}$, M. Manuela M. Raposo ${ }^{c}$, Paulo J. Coelho ${ }^{d}$, Andrew Ng Kay Lup ${ }^{\mathrm{e}}$, \\ Alireza Soltani ${ }^{\mathrm{f}, *}$ \\ a Department of Organic E Inorganic Chemistry, Faculty of Chemistry, Urmia University, Urmia 57159, Iran \\ ${ }^{\mathrm{b}}$ Department of Chemistry and Biotechnology, Swinburne University of Technology, Hawthorn VIC 3122, Australia \\ ' Centro de Química, Universidade do Minho, Campus de Gualtar, Braga 4710-057, Portugal \\ ${ }^{d}$ Centro de-Química- Vila Real, Universidade de Tràs-os-Montes e Alto Douro, Vila Real 5001-801, Portugal \\ e School of Energy and Chemical Engineering, Xiamen University Malaysia, Jalan Sunsuria, Bandar Sunsuria, Sepang 43900, Selangor Darul Ehsan, Malaysia \\ ${ }^{\mathrm{f}}$ Golestan Rheumatology Research Center, Golestan University of Medical Science, Gorgan, Iran
}

\section{A R T I C L E I N F O}

\section{Article history:}

Received 9 July 2020

Revised 15 September 2020

Accepted 21 September 2020

Available online 23 September 2020

\section{Keywords:}

8-hydroxyquinoline

5-hydroxyquinoline

Heterocyclic azo dyes

Tautomerism

Solvatochromism

Photochromism

\begin{abstract}
A B S T R A C T
A series of novel substituted-azo dyes 8-(aryldiazenyl)quinolin-5-ol (5a-i) were synthesized by the coupling reaction of 5-hydroxyquinoline with diazotized aniline derivatives in the presence of $\mathrm{NaNO}_{2}$ in $\mathrm{HCl} / \mathrm{H}_{2} \mathrm{O}$ mixture. The study of the spectroscopic and solvatochromic properties were performed by FTIR, ${ }^{1} \mathrm{H}$ and ${ }^{13} \mathrm{C}$-NMR and UV-Visible spectroscopies. The tautomerism of these dyes was studied using the deuteration technique and solvatochromic measurements. Photochromic properties of these 5hydroxyquinoline azo dyes were also examined via $E / Z$ and $Z / E$ photochemical isomerization reactions and compared with the existing 8-hydroxyquinoline analogous. The novel substituted-azo dyes exhibited higher $Z / E$ thermal isomerization rates and have larger absorbance wavelength range than their 8hydroxyquinoline analogous, making them potential molecular switches.
\end{abstract}

(c) 2020 Elsevier B.V. All rights reserved.

\section{Introduction}

Organic dye chemistry is facing a very interesting development as a result of their application in different research fields including electronic [1], linear and nonlinear optics [2], reprography [3], sensors and biological technologies [4]. Mono-azo dyes are the most significant type of azo dyes [5-8] and have found applications in memory and recording devices [9,10], molecular switches [11,12], thermochromic [13], photovoltaic fluorescent devices [14,15], supramolecular systems [16,17], halographic data storage materials [18], and metal sensors [19]. Their synthesis route [20], absorptivity [21,22], solubility $[23,24]$ and stability $[25,26]$ have been deeply studied.

The biological properties, coordination and metal extraction ability have made quinoline and its derivatives very important compounds [27]. Several quinoline derivatives show medicinal

\footnotetext{
* Corresponding authors.

E-mail addresses: mramezanitaghartapeh@swin.edu.au (M. Ramezanitaghartapeh), alireza.soltani@goums.ac.ir (A. Soltani).
}

properties such as antimalarial, anti-allergy, antivirus, and antiinfection [28,29].

8-hydroxyquinoline, 8HQ (Fig. 1A) is one of the well-known derivatives bearing the quinoline core which is widely used in inorganic chemistry due to its chelating properties for a wide range of metal ions [30-32]. Its derivatives show also antibacterial activities [33]. Furthermore, some efficient chromophoric and metallochromic indicators have $8 \mathrm{HQ}$ in their structure [34]. The presence of a stable chromophore azo group $(-\mathrm{N}=\mathrm{N}-)$ conjugated with an aromatic ring creates a molecule with intense and highly stable color in different solvents throughout the visible region of light [35-38]. Although numerous papers have described the synthesis and properties of azo-8-hydroxyquinoline [39-42], there is no report on the synthesis of similar 5-hydroxyquinoline (5HQ) azo analogous (Fig. 1B). Therefore, the study of the photophysical properties of $5 \mathrm{HQ}$ may provide further insights on its potential as molecular switches compared to the 8HQ analogs. Recently, the effect of substitution, temperature, concentration, solvent, acid and base addition on the visible absorption spectra of several heteroarylazo dyes was performed by Seferoğlu and coworkers [4347], and Ertan and coworkers studied the solvatochromism of some 
<smiles>Oc1cccc2ncccc12</smiles>

Fig. 1. Molecular structures of 8-hydroxyquinoline (A) and 5-hydroxyquinoline (B).

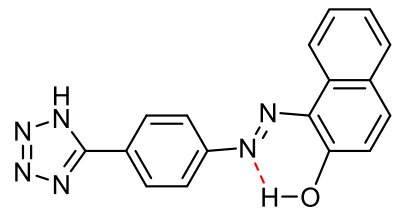

Fig. 2. Intramolecular $\mathrm{H}$-bond in azo dyes based on $\beta$-naphthol [63].

heteroarylazo-8HQ dyes. They showed that the tautomeric equilibrium was deeply solvent dependent and that the azo form was predominant in polar-aprotic solvents such as dimethylsulfoxide (DMSO) and dimethylformamide (DMF) $[48,49]$.

The photochemical $E-Z$ isomerization of aromatic azo dyes (Scheme S1), in solution or incorporated in polymeric matrices, is a well-established phenomenon that has been the subject of intense research [50]. Under the UV light irradiation, the thermally stable $E$-isomer is partially converted to the meta-stable Z-isomer resulting in a photostationary equilibrium between the two isomers. The $Z$-isomers is thermally unstable and returns spontaneously back to the initial $E$-form. However, in some cases, the $Z$-isomer is thermally stable and then the back reaction can be promoted using the light of a different wavelength (Fig. S1). Despite numerous studies, the mechanism for this interconversion is not completely clear. Two major competitive mechanisms can be considered: the inplane inversion mechanism involving the sp hybridization of one nitrogen atom [51] and the rotational mechanism [52]. The dynamics of these dyes are also very dependent on their substitution pattern and environment [53].

These azo-aromatic chromophores enable a fully reversible and clean photoreaction creating a valuable photochemical system. The spatial arrangement of $E$-isomer molecule allows an effective extension of the $\pi$-conjugation while the same phenomenon is not possible for the $Z$-isomer since the two aromatic rings are not in the same plane. Consequently, the thermally stable E-isomer exhibits a much more intense optical absorption than the $Z$-isomer [54]. The azo isomerization reaction requires a large geometrical change within the molecular configuration and is therefore sensitive to the steric effects. Moreover, these molecules show a great tendency to aggregate, especially if they are not soluble in a solvent, which leads to self-assembly resulting in the inhibition of the photo-isomerization process [55,56]. As the reversible structural changes occur at a single-molecule level, these molecules are very interesting for fully photon-controlled applications such as the photo-switchers technologies [57] and also for their physicochemical properties (e.g. fluorescence, electrical conductivity, magnetism, permeability, and reactivity) [58,59].

In this work, it was studied the solvatochromism of new arylazo-5HQ and compare them to their $8 \mathrm{HQ}$ analogs. The different substitution of the basic hydroxyl group relative to the basic quinoline core is predicted to have an impact on its azo/hydrazone equilibrium. Nevertheless, this study attempts to investigate and relate its effects qualitatively and quantitatively with the spectrokinetics performance of 5HQ. Besides, the dyes tautomerism was evaluated by ${ }^{13} \mathrm{C}$ NMR using the deuterium isotope effect $[60,61]$ which showed that the position of the carbonyl(hydroxyl) on the quinoline ring has a significant effect on the spectrokinetic of these dyes. The photoswitching properties of the $5 \mathrm{HQ}$ azo derivatives were also investigated to determine their potential application as molecular switches.

\section{Experimental}

\subsection{General}

For the measurement of ${ }^{1} \mathrm{H}$ NMR and ${ }^{13} \mathrm{C}$ NMR spectra of azo dyes, $\mathbf{4}(\mathbf{a}-\mathbf{i})$ and $\mathbf{5}(\mathbf{a}-\mathbf{i})$ were dissolved in $\mathrm{CDCl}_{3}$ and/or $\left(\mathrm{CD}_{3}\right)_{2} \mathrm{SO}$ (99.8\%) and partial deuteration was achieved by the addition of two drops of $\mathrm{D}_{2} \mathrm{O}$ and/or $\mathrm{CD}_{3} \mathrm{OD}$. The ${ }^{1} \mathrm{H}$ NMR and ${ }^{13} \mathrm{C}$ NMR spectra were recorded on a Bruker 300 FT-NMR spectrometer (300 $\mathrm{MHz}$ for ${ }^{1} \mathrm{H}, 75 \mathrm{MHz}$ for ${ }^{13} \mathrm{C}$ ) in $\mathrm{CDCl}_{3}$ and/or $\left(\mathrm{CD}_{3}\right)_{2} \mathrm{SO}$, at room temperature $\left(25{ }^{\circ} \mathrm{C}\right)$ using $5 \mathrm{~mm}$ direct detection broad band probes and deuterium lock (Urmia University, Urmia, Iran). The center of the solvent of $\left(\mathrm{CD}_{3}\right)_{2} \mathrm{SO}$ signal was used as an internal standard which was related to tetramethylsilane with $\delta=2.49 \mathrm{ppm}\left({ }^{1} \mathrm{H}\right)$ and a septet at $\delta=39.5 \mathrm{ppm}\left({ }^{13} \mathrm{C}\right)$ and for the solvent of $\mathrm{CDCl}_{3}$ signal was $\delta=7.27 \mathrm{ppm}\left({ }^{1} \mathrm{H}\right.$, corresponds to the trace $\mathrm{CHCl}_{3}$ as an impurity) and a triplet at $\delta=77.06 \mathrm{ppm}\left({ }^{13} \mathrm{C}\right)$. Also, the center of the added solvent of $\mathrm{CD}_{3} \mathrm{OD}$ signal appeared as septet at $\delta=48.04 \mathrm{ppm}\left({ }^{13} \mathrm{C}\right)$. The ${ }^{1} \mathrm{H}$ signal of HDO appeared at $\delta=3.70 \mathrm{ppm}$ (variable). The recording conditions were as follows: ${ }^{1} \mathrm{H}$ NMR: pulse width $\left(90^{\circ}\right)=8.2 \mu \mathrm{s}$, acquisition time $=2.65 \mathrm{~s}$, digital resolution $=0.19 \mathrm{~Hz} /$ data point, $\mathrm{d} 1=1 \mathrm{~s}, \mathrm{td}=32768, \mathrm{~ns}=16$, experimental time $=64 \mathrm{~s}$, spectral width $=6172.8 \mathrm{~Hz}, \mathrm{rg}=4597.6$, $\mathrm{dw}=81 \mu \mathrm{s}$, de $=6 \mu \mathrm{s} ;{ }^{13} \mathrm{C}$ NMR: pulse width $\left(90^{\circ}\right)=6.3 \mu \mathrm{s}$, acquisition time $=1.82 \mathrm{~s}$, digital resolution $=0.27 \mathrm{~Hz} /$ data point, $\mathrm{d} 1=2 \mathrm{~s}, \mathrm{td}=65536, \mathrm{~ns}=1000$, experimental time $=3922 \mathrm{~s}$, spectra width $=17985.6 \mathrm{~Hz}, \mathrm{rg}=5792.6, \mathrm{dw}=27.8 \mu \mathrm{s}$, de $=6 \mu \mathrm{s}$.

For the characterization of synthesized azo dyes, IR spectra were performed in the range of $4000-400 \mathrm{~cm}^{-1}$ on a NEXUS 670 FT IR spectrometer by preparing $\mathrm{KBr}$ pellets (Urmia University, Urmia, Iran). Melting points were determined with a digital melting point apparatus (Electrotermal) and were uncorrected. 5Hydroxy quinoline (5HQ), 8-hydroxy quinoline (8HQ), anilines and its derivatives and deuterated solvents $\left(\left(\mathrm{CD}_{3}\right)_{2} \mathrm{SO}, \mathrm{CDCl}_{3}, \mathrm{CD}_{3} \mathrm{OD}\right.$ and $\mathrm{D}_{2} \mathrm{O}$ ) were purchased from Merck and Sigma-Aldrich.

\subsection{Synthesis}

The 8-HQ and 5-HQ mono-azo dyes (4 and $\mathbf{5}$ ) were synthesized using a similar method described before [62]. A mixture of aniline and/or its derivatives $(1.0 \mathrm{mmol})$, water $(10 \mathrm{ml})$, and conc. $\mathrm{HCl}$ (3.0 mmol) was cooled to $0{ }^{\circ} \mathrm{C}$. Aqueous $\mathrm{NaNO}_{2}(1.0 \mathrm{mmol})$ was added with stirring at such a rate as to prevent a temperature rise. The mixture was kept at $0{ }^{\circ} \mathrm{C}$ for $10 \mathrm{~min}$ and added in portions to a solution of $8 \mathrm{HQ}$ and/or $5 \mathrm{HQ}(1.1 \mathrm{mmol})$ in THF $(25 \mathrm{ml})$ and acetic acid or their mixture with a saturated aqueous solution of sodium acetate $(0.01 \mathrm{gr}$ per every $10 \mathrm{mmol}$ of aniline). The reaction mixture was continuously stirred for several hours. The precipitated dye was filtered off, washed with water and cold isopropyl alcohol, and dried at $20-30{ }^{\circ} \mathrm{C}$.

\section{Result and discussion}

\subsection{Synthesis and spectroscopic characterizations}

5-(Aryldiazenyl)quinolin-8-ols (4a-i) were prepared by the coupling reaction of 8 -hydroxyquinoline $(8 \mathrm{HQ})$ with diazotized aniline derivatives with $\mathrm{NaNO}_{2}$ in a $\mathrm{HCl} / \mathrm{H}_{2} \mathrm{O}$ mixture (Scheme 1a) [62]. The 8-(Aryldiazenyl)quinolin-5-ols (5a-i) were prepared from 5-hydroxyquinoline (5HQ) using the same method of synthesis (Scheme 1b). Some organic azo dyes derived from $\beta$-naphthol and its derivatives show an intramolecular $\mathrm{H}$-bond between $\mathrm{OH}$ group and azo nitrogen (Fig. 2) [63]. The corresponding proton chemical 


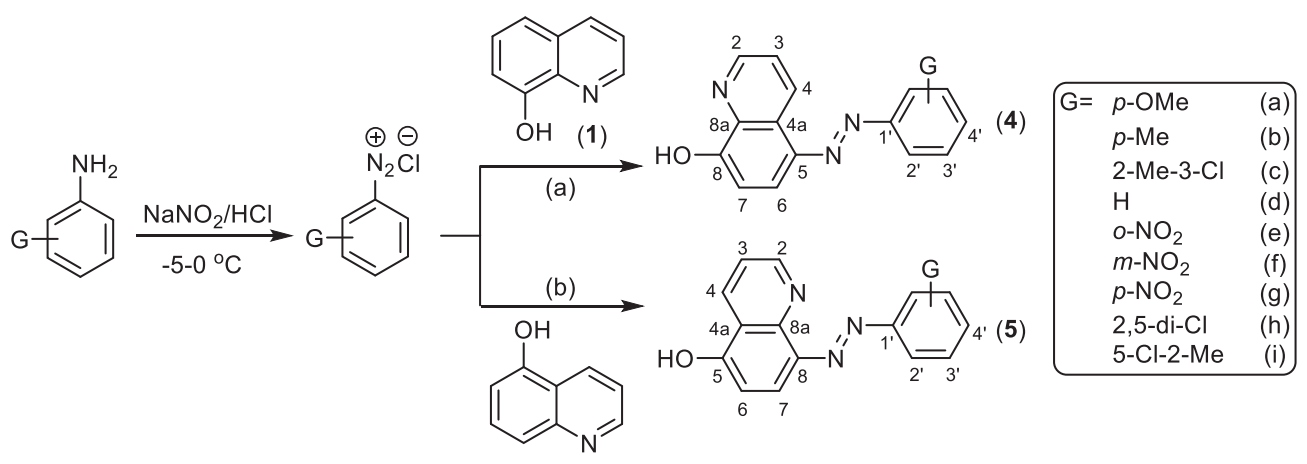

(2)

Scheme 1. General reaction for the synthesis of azo dyes $\mathbf{4 a - i}$ and $\mathbf{5 a - i}$.

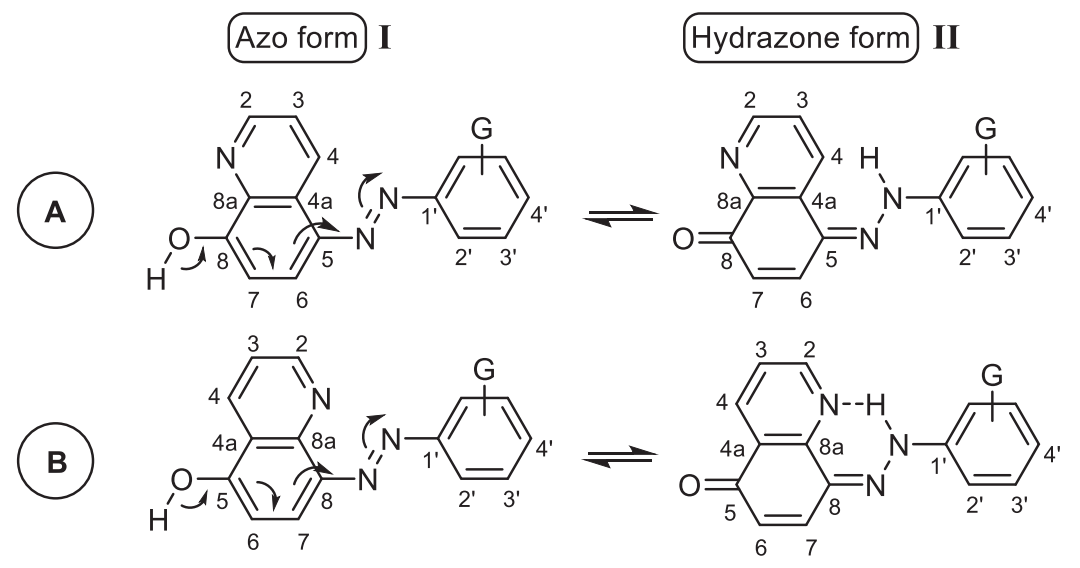

Scheme 2. General tautomerization for azo dyes $\mathbf{4 a - i}(\mathbf{A})$, and $\mathbf{5 a - i}(\mathbf{B})$.

shift in the ${ }^{1} \mathrm{H}$ NMR spectra of these compounds deshields up to $\delta 14 \mathrm{ppm}$ which confirms the coupling from the $\mathrm{OH}$ vicinal position [63]. In the present work, the absence of the highly deshielded proton (around $14 \mathrm{ppm}$ ) confirms that no intramolecular $\mathrm{H}$-bonds are present, which was expected if the reaction had occurred in the $\mathrm{OH}$ vicinal position (7-position for 8HQ dyes and 6-position for 5HQ dyes) (Scheme 1). Detailed data of ${ }^{1} \mathrm{H}$ and ${ }^{13} \mathrm{C}$ NMR and FT-IR spectroscopies are available in the experimental section.

The general azo/hydrazone tautomerism in (4a-i) and (5ai) azo dyes is depicted in Scheme 2. The azo/hydrazone tautomerism of $8 \mathrm{HQ}$ dyes substituted with benzothiazolo [49,42] and 4-cyanophenylazo [64] groups ar quite influenced by the solvent nature. Electron-donating substituents shift the tautomeric equilibrium towards the azo form, while an electron-withdrawing group favors the hydrazone form [42]. The azo/hydrazone ratio of some (aryldiazenyl)quinoline-8-ol dyes [64], evaluated by NMR, was largely influenced by the position of electron-withdrawing groups. The azo form predominates in polar solvents such as DMF [65] and these dyes exist entirely in the azo form in some anisotropic media as these solvents provide relatively rigid, packed and polarizable media which prevent the azo/hydrazone tautomerism [65]. Besides that, the hydroxyl group of azo tautomer and the protonated nitrogen group of hydrazone tautomer are both able to form hydrogen bonds with certain solvents. Both groups will form hydrogen bonds with different extensions as hydroxyl is a stronger hydrogen bond donor. Thus, hydrogen bond acceptor (HBA) solvents such as dichloromethane (DCM) and DMF (dimethylformamide) will tend to stabilize the azo form through their hydrogen bonding with the hydroxyl group of azo tautomer whereas hydrogen bond donor (HBD) solvents such as methanol will tend to stabilize the hydra- zone form through their hydrogen bonding with the protonated nitrogen of hydrazone tautomer.

The 5HQ dyes (5) can exist in two tautomeric forms: the azoform (5[I]) and hydrazone-form (5[II]) (Scheme 2B). Curiously the hydrazone form (5[II]) has an intramolecular hydrogen bond with the nitrogen atom of the quinoline ring moiety (Scheme 2B). For dye $\mathbf{5 e}$, with an ortho-nitro function, a bifurcated intramolecular hydrogen bond with one oxygen of the nitro group and the nitrogen atom of the quinoline heterocycle can be expected (Scheme 3) $[60,61,66]$.

The FT-IR spectra of dyes $\mathbf{4}$ and $\mathbf{5}$ showed four distinct transmittance peaks at $3200-3280 \mathrm{~cm}^{-1}, 1500-1515 \mathrm{~cm}^{-1}, 1550-$ $1600 \mathrm{~cm}^{-1}$ and $1220-1250 \mathrm{~cm}^{-1}$ which correspond to the $\mathrm{O}-\mathrm{H}$, $\mathrm{C}=\mathrm{O}, \mathrm{N}=\mathrm{N}$ and $\mathrm{C}-\mathrm{O}$ functional groups, respectively. The presence of $\mathrm{C}=\mathrm{O}$ and $\mathrm{C}-\mathrm{O}$ groups indicated that the azo dyes exist in azo/hydrazone tautomeric equilibrium. For nitro-substituted azo dyes, the C-O peaks were significantly shifted to $1345-1355 \mathrm{~cm}^{-1}$ indicating the destabilization of azo tautomers as bifurcated intramolecular hydrogen bonds are formed in the hydrazone tautomers. The comprehensive and detailed spectra and interpretations of FT-IR and ${ }^{1} \mathrm{H}$ and ${ }^{13} \mathrm{C}$ NMR characterizations were provided as supplementary material (Figs. S2-S93).

\subsection{Isotopic splitting pattern in the ${ }^{13} \mathrm{C}-\mathrm{NMR}$ spectra}

The ${ }^{13} \mathrm{C}$ NMR spectrum of dyes $\mathbf{5 a}$ and $\mathbf{5 b}$ shows two distinct signals for the methoxy group (5a) at $\delta 56.38$ and $54.86 \mathrm{ppm}$ and methyl group (5b) at $\delta 21.50$ and 20.47 ppm, respectively, which confirms the existence of two tautomeric forms in equilibrium (Fig. 3A). See supporting information for all ${ }^{13} \mathrm{C}$ NMR spectra of the corresponding dyes. 

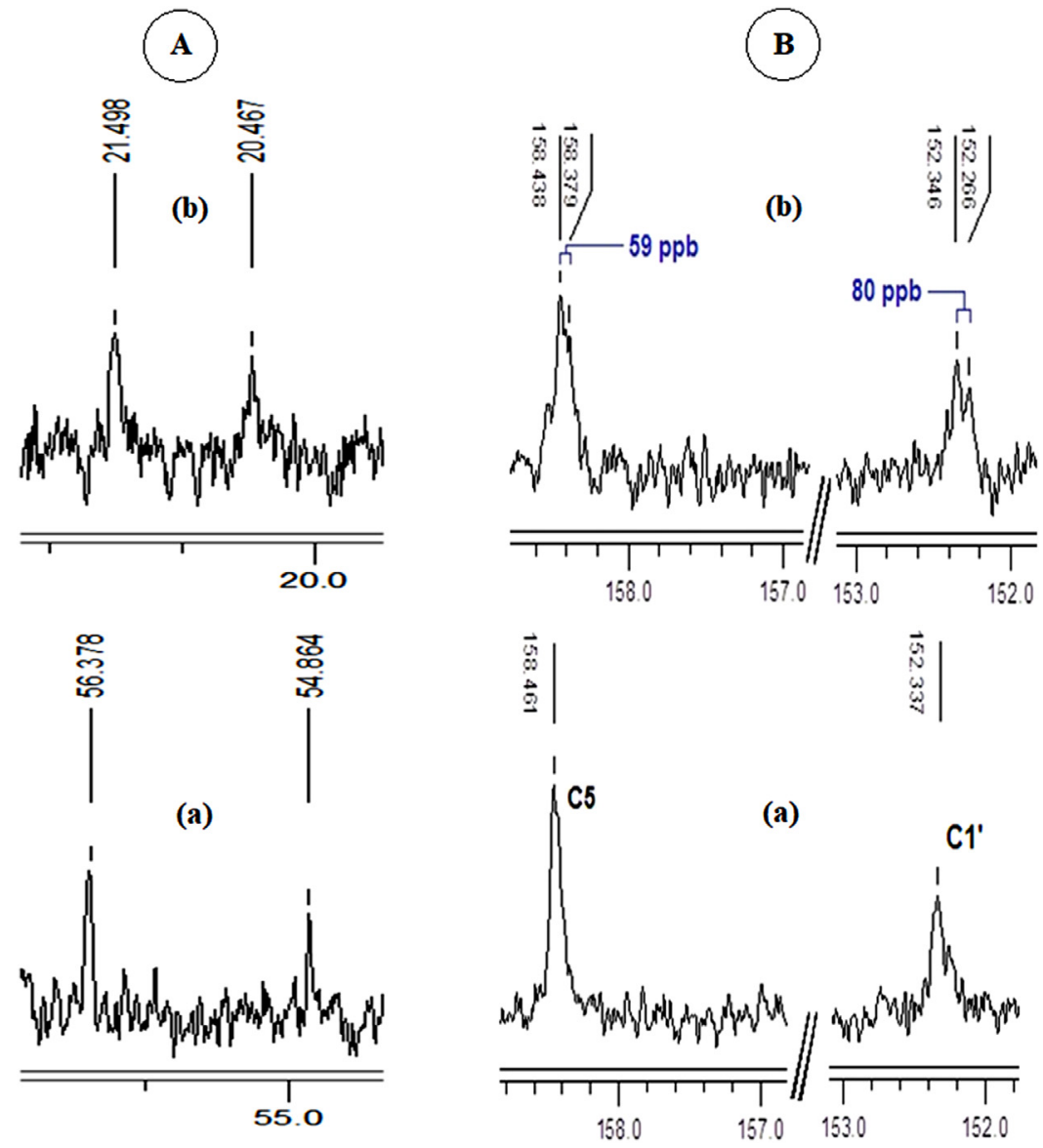

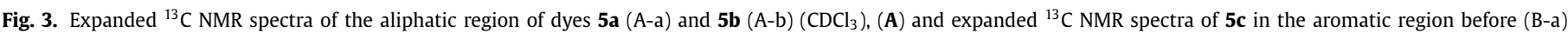
and after adding two drops of $\mathrm{CD}_{3} \mathrm{OD}$ (B-b), (B).

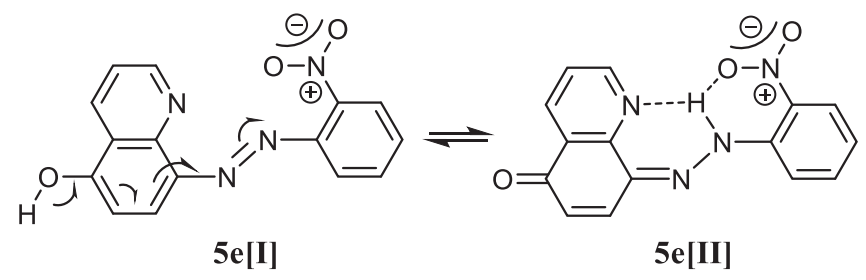

Scheme 3. Bifurcated intramolecular H-bond in $\mathbf{5 e}$ in hydrazone-form $\mathbf{5 e}[\mathbf{I I}]$

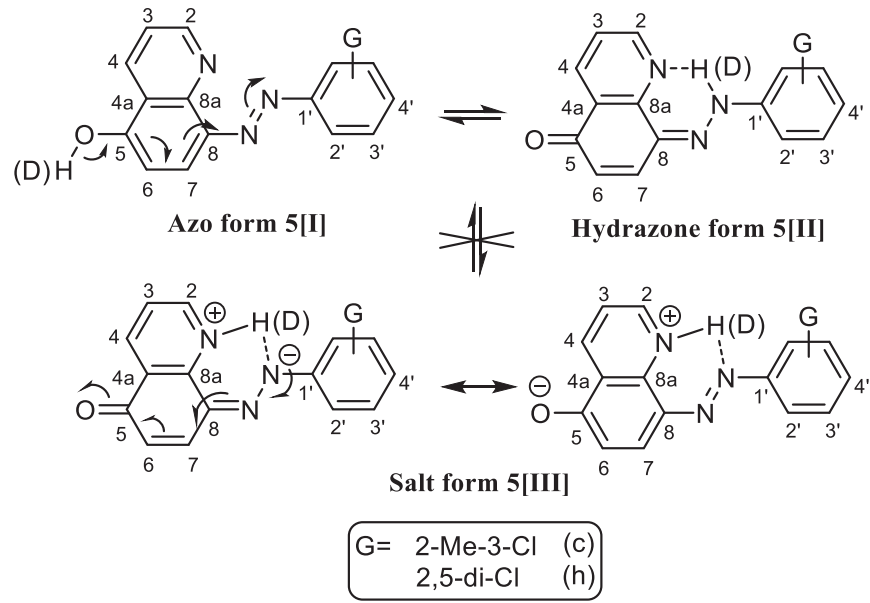

Scheme 4. Possible and impossible form of tautomerism in $\mathbf{5 c}$ and $\mathbf{5 h}$.
Deuterium isotope effects on carbon-13 chemical shifts are of great potential use for spectral assignments and structure determination $[60,61,67]$. These effects unambiguously reveal the chemical shifts of the carbon atoms in the neighborhood of the deuterium atom $[68,69]$. The isotope exchange process between water or any other protic solvent and easily exchangeable groups (e.g. $\mathrm{O}-\mathrm{H}, \mathrm{N}-\mathrm{H}$ and $\mathrm{S}-\mathrm{H}$ ) are of interest for the study of reaction mechanism and elucidation of the structural dynamics in biological macromolecules [70]. The process takes place in two steps: (1) recording a normal ${ }^{13} \mathrm{C}$ NMR spectrum from the sample, and (2) adding a few drops of the second deuterated solvent (e.g. $\mathrm{D}_{2} \mathrm{O}$, $\mathrm{CD}_{3} \mathrm{OD}$, etc. depending this fact that the second solvent does not cause the compound precipitate in the tube) to the same NMR tube and re-recording the spectrum. This action leads to isotopic shifts and splitting of the resonance of the carbon atoms bearing exchangeable hydrogen $[71,72]$. This investigation needs a delicate attention since the changes are sometimes within ppb [60,61,67]. In the present work, the addition of a few drops of deuterated methanol $\left(\mathrm{CD}_{3} \mathrm{OD}\right)$ caused the splitting of the carbon signals. As an example, Fig. 3B presents the isotopic splitting of the ${ }^{13} \mathrm{C}$ NMR signals of carbons $\mathrm{C} 5$ and $\mathrm{C}^{\prime}$ of $\mathbf{5 c}$ (in DMSO) before and after the addition of two drops of $\mathrm{CD}_{3} \mathrm{OD}$. The $\mathrm{C}^{\prime}$ and $\mathrm{C} 5$ atoms appear as singlets at 152.337 and 158.461 in DMSO. After the addition of a few drops of $\mathrm{CD}_{3} \mathrm{OD}$, carbon $\mathrm{C} 5$ ( $\alpha$ to $\mathrm{OH}$ ) shows a doublet with signals at $\delta=158.438$ and $158.379 \mathrm{ppm}(\Delta \delta=59 \mathrm{ppb})$, and the $\mathrm{C}^{\prime}{ }^{\prime}$ carbon atom resonates at $\delta=152.346$ and $152.266 \mathrm{ppm}$ $(\Delta \delta=80 \mathrm{ppb})$. These observations indicate that the two carbon atoms ( $\mathrm{C} 5$ and $\mathrm{C}^{\prime}$ ) show a $\beta$-isotope effect demonstrating the 
Table 1

Selected ${ }^{13} \mathrm{C}$ NMR data for azo dyes derived from 5-HQ (5a-h) and 8-HQ (4a-h) before and after adding two drops of $\mathrm{D}_{2} \mathrm{O}$ and/or $\mathrm{CD}_{3} \mathrm{OD}$ (in case we had problem obtaining a clear and accurate spectra using $\mathrm{D}_{2} \mathrm{O}$ due to the solubility issue of the samples in $\mathrm{D}_{2} \mathrm{O}$ ).

\begin{tabular}{|c|c|c|c|c|c|c|}
\hline Entry & Dyes & $\mathrm{C} 2$ & $\mathrm{C} 5$ & $\mathrm{C} 8$ & $\mathrm{C} 8 \mathrm{a}$ & $\mathrm{C} 1^{\prime}$ \\
\hline \multirow[t]{2}{*}{1} & $5 c^{b, c}$ & 139.453 & 158.461 & 138.328 & 135.334 & 152.337 \\
\hline & & 139.479 & $158.438,158.379$ & 138.308 & 135.320 & $152.346,152.266$ \\
\hline \multirow[t]{2}{*}{2} & $\mathbf{5 h}^{\mathrm{b}, \mathrm{c}}$ & 139.362 & 159.474 & 138.225 & 133.554 & 149.444 \\
\hline & & 139.350 & 159.469 & 138.223 & 133.537 & $149.477,149.437$ \\
\hline \multirow[t]{2}{*}{3} & $\mathbf{4} \mathbf{b}^{\mathrm{d}, \mathrm{e}}$ & - & - & 155.060 & - & 148.81 \\
\hline & & - & - & $155.012,154.974$ & - & 148.83 \\
\hline \multirow[t]{2}{*}{4} & $\mathbf{4} \mathbf{d}^{\mathrm{b}, \mathrm{c}}$ & - & - & 157.989 & - & 152.973 \\
\hline & & - & - & 157.960 & - & $152.997,152.945$ \\
\hline
\end{tabular}

a The peaks intensity of $\mathbf{4 c}, \mathbf{4 e}$ and $\mathbf{4 f}$ were low.

b before adding two drops of $\mathrm{CD}_{3} \mathrm{OD}$.

c after adding $\mathrm{CD}_{3} \mathrm{OD}$.

$\mathrm{d}$ before adding $\mathrm{D}_{2} \mathrm{O}$.

e after adding $\mathrm{D}_{2} \mathrm{O}$.
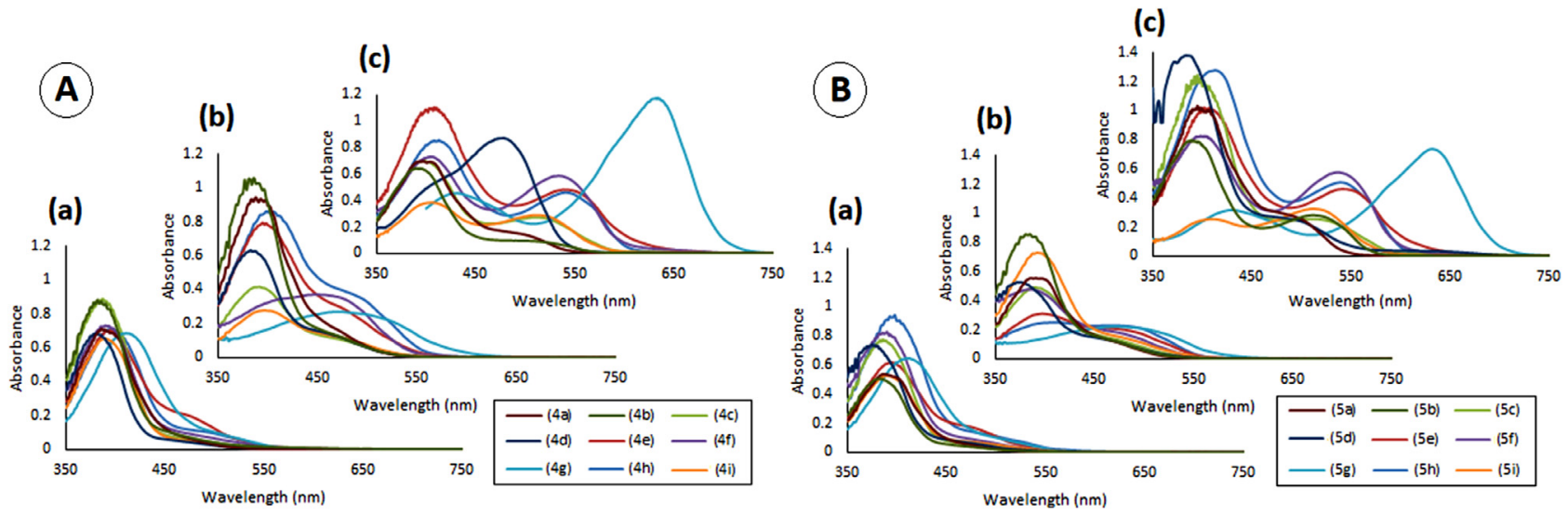

Fig. 4. Absorption spectra of 4a-i (A) and 5a-i (B) in: (a) DCM, (b) methanol, (c) DMF.

existence of an equilibrium between two isomeric forms [72,73] (Scheme 4).

However, for dye $\mathbf{5 h}, \mathrm{C}^{\prime}$ carbon atom shows nearly two singlets at $\delta=149.477$ and $149.437 \mathrm{ppm}(\Delta \delta=40 \mathrm{ppb})$ while the C5 shows one singlet at $159.469 \mathrm{ppm}$. These observations denote the presence of the hydrazone form ( $\mathbf{5 h}[\mathrm{II}])$ in the dye $\mathbf{5 h}$. As it is shown in the Table 1, the C2 and C8a carbons in $\mathbf{5 c}$ and $\mathbf{5 h}$ do not show $\beta$-isotope effect. Therefore, it could be concluded that the generation of $\mathbf{5}[\mathrm{III}]$ in its salt form is not favored (Scheme 4, Table 1).

A similar investigation was carried out for dyes $\mathbf{4 b}$ and $\mathbf{4 d}$ as representative examples for series 4 . The $\beta$-isotope effect in $\mathrm{C}^{\prime}$ for 4d (two singlet at $\delta=152.997$ and 152.945 with $\Delta \delta=52 \mathrm{ppb}$ ) denotes the hydrazone form in this compound. However, $\beta$-isotope effect for $\mathbf{4 b}$ occurs just in C8 $(\delta=155.012$ and 154.947 with $\Delta \delta=65 \mathrm{ppb}$ ) demonstrating the azo form in this dye (Table 1 ). The solvatochromic studies also strengthens these observations (see Section 3.3).

\subsection{UV-spectroscopy, solvent effect on absorption spectra of compounds in various solvents}

For these dyes, two possible transitions are expected (the $\pi \rightarrow \pi^{*}$ and $n \rightarrow \pi^{*}$ ), which are however dependent on the nature of the functional group as well as the dipole moment of the solvent used for the UV-Vis spectroscopy measurement (Figs. S94S99) [74]. Since the tautomeric equilibrium of a dye molecule is strongly dependent on the nature of its environment $[75,76]$, the solvatochromic behavior of the dyes in various solvents was studied. For this purpose, the absorption spectra of $\mathbf{4 a - i}$ and $\mathbf{5 a - i}$ dyes
Table 2

Maximum wavelength of absorption of dyes $\mathbf{4 a - i}$ and $\mathbf{5 a - i}$ in various solvents.

\begin{tabular}{llllll}
\hline Entry & Dye label & $\mathrm{G}$ & $\mathrm{DCM}$ & $\mathrm{DMF}$ & Methanol \\
\hline 1 & $\mathbf{4 a}$ & $p-\mathrm{OMe}$ & 386 & $398,491 \mathrm{~s}$ & 388 \\
2 & $\mathbf{4 b}$ & $p-\mathrm{Me}$ & 382 & $389,508 \mathrm{~s}$ & $386,466 \mathrm{~s}$ \\
3 & $\mathbf{4 c}$ & $3-\mathrm{Cl}-2-\mathrm{Me}$ & 387 & 398,511 & $392,466 \mathrm{~s}$ \\
4 & $\mathbf{4 d}$ & $\mathrm{H}$ & 381 & $411 \mathrm{~s}, 478$ & $382,453 \mathrm{~s}$ \\
5 & $\mathbf{4 e}$ & $0-\mathrm{NO}_{2}$ & $395,477 \mathrm{~s}$ & 408,539 & $395,480 \mathrm{~s}$ \\
6 & $\mathbf{4 f}$ & $m-\mathrm{NO}_{2}$ & 390 & 406,534 & 453 \\
7 & $\mathbf{4 g}$ & $p-\mathrm{NO}_{2}$ & 411 & 431,634 & 472 \\
8 & $\mathbf{4 h}$ & $2,5-\mathrm{di}^{-C l}$ & $397,498 \mathrm{~s}$ & 413,542 & $399,484 \mathrm{~s}$ \\
9 & $\mathbf{4 i}$ & $5-\mathrm{Cl}-2-\mathrm{Me}$ & 390 & 405,514 & $397,467 \mathrm{~s}$ \\
10 & $\mathbf{5 a}$ & $p-\mathrm{OMe}$ & 386 & $395,478 \mathrm{~s}$ & 391 \\
11 & $\mathbf{5 b}$ & $p-\mathrm{Me}$ & 384 & 389,514 & 385 \\
12 & $\mathbf{5 c}$ & $3-\mathrm{Cl}-2-\mathrm{Me}$ & 386 & $395,510 \mathrm{~s}$ & $390,468 \mathrm{~s}$ \\
13 & $\mathbf{5 d}$ & $\mathrm{H}$ & 375 & $384,481 \mathrm{~s}$ & $372,455 \mathrm{~s}$ \\
14 & $\mathbf{5 e}$ & $0-\mathrm{NO}_{2}$ & $395,470 \mathrm{~s}$ & 402,543 & $397,472 \mathrm{~s}$ \\
15 & $\mathbf{5 f}$ & $m-\mathrm{NO}_{2}$ & 390 & 398,536 & $383,474 \mathrm{~s}$ \\
16 & $\mathbf{5 g}$ & $p-\mathrm{NO}_{2}$ & 412 & 429,633 & 474 \\
17 & $\mathbf{5 h}$ & $2,5-\mathrm{di} \mathrm{Cl}$ & $398,492 \mathrm{~s}$ & 408,541 & $414,468 \mathrm{~s}$ \\
18 & $\mathbf{5 i}$ & $5-\mathrm{Cl}-2-\mathrm{Me}$ & 388 & 408,513 & $392,472 \mathrm{~s}$ \\
\hline
\end{tabular}

s: Shoulder.

were measured in various solvents at a concentration of $10^{-3} \mathrm{M}$ (Table 2). All absorptions are depicted in Fig. 4.

A similar study was carried out for some derivatives of $\mathbf{4}$ by Saylam et.al [49]. It was found that the absorption maxima of these dyes are strongly dependent on the solvent polarity. The dyes show generally a bathochromic shift as the polarity of solvent increases from DCM $(P=3.1)$, methanol $(P=5.1)$ to DMF $(P=6.4)$ where $P$ is the solvent polarity index [48].

Dyes 5a-i show nearly one absorption maximum in dichloromethane with exception for $\mathbf{5 e}$ and $\mathbf{5 h}$ (Table 2) in 

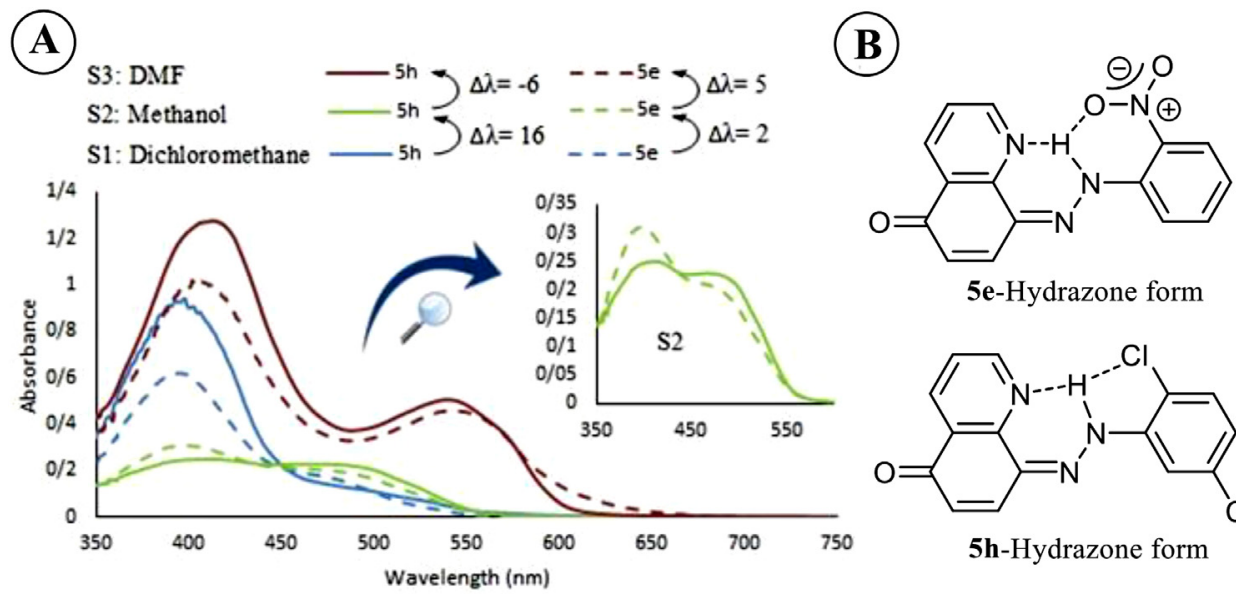

Fig. 5. Absorption spectra of $\mathbf{5 e}$ and $\mathbf{5 h}$ in DCM, in methanol and in DMF (A), and hydrazone-form tautomer of $\mathbf{5 e}$ and $\mathbf{5 h}$ (B).

their corresponding UV-visible spectrum indicating a dominant single tautomeric form of these dyes in dichloromethane solvent. The absorption spectra of dyes $\mathbf{5 e}$ and $\mathbf{5 h}$ display one absorption maximum with a shoulder in DCM and methanol and two absorption maxima in DMF (Table 2, Fig. 5A). The existence of either two absorption maxima in DMF or a shoulder indicates for two forms of tautomers (as an equilibrium mixture of two tautomers) [49]. It is then proposed that dyes $\mathbf{5 e}$ and $\mathbf{5 h}$ exist as a mixture of tautomeric forms in all used solvents. However, having asymmetric and unbalanced absorbance shows that one tautomeric form dominates the other. It is well-known that increase in the polarity of a solvent the shifts the tautomerization equilibria to hydrazone form [77], therefore a different mixture ratio of tautomers were observed due to the change in the solvent used in order of dichloromethane $\rightarrow$ methanol $\rightarrow$ DMF where the shoulders in dichloromethane and methanol gradually become a distinct peak in DMF. The partial appearance of hydrazone-form in dye $\mathbf{5 h}$ in dichloromethane is well-agreed with the obtained result of the isotopic splitting pattern in the previous section.

Considering the tautomerization of dyes $\mathbf{5 e}$ and $\mathbf{5 h}$, the existence of nitro $\left(\mathrm{NO}_{2}\right)$ or Chlorine $(\mathrm{Cl})$ on the ortho-position of phenyl ring makes them different from other derivatives. Interaction between these groups $[61,66,67]$ and the hydrogen atom of the hydrazone form brings a relative stability to the hydrazone form compared to other dyes in this series (Fig. 5B). Similar results were obtained for dyes $\mathbf{4 e}$ and $\mathbf{4 h}$.

In order to investigate the bifurcated intramolecular $\mathrm{H}$-bond and its effect on the stability of hydrazone form, dyes $\mathbf{5 e}, \mathbf{5 f}$ and $\mathbf{5 g}$ with nitro group on different positions of the phenyl ring could be further analyzed. It was observed that the maximum of the absorption bond of hydrazone form appears at a longer wavelength compared to the azo form $[49,78,79]$. Although the azo form is highly dominant in all obtained spectra of these dyes, a relative stability of hydrazone form in dye $\mathbf{5 e}$ in dichloromethane is more obvious than hydrazone form in dyes $\mathbf{5 f}$ and $\mathbf{5 g}$. See Fig. $6 \mathrm{~A}-\mathrm{C}$ for more details, in which it could be observed the appearance of a shoulder in right hand side of the peak maxima of 5e (Fig. 6A). With the increase of the polarity of solvent (dichloromethane $\rightarrow$ methanol), the azo form is the main tautomer for dyes $\mathbf{5 e}$ and $\mathbf{5 f}$, but the stability of hydrazone form also appears in both compounds. This is despite the fact that dye $\mathbf{5 g}$ does not show a shoulder and it has a maximum peak in the middle region (Fig. 6B). In comparison with the next solvent (DMF), it can be concluded that $\mathbf{5 g}$ in methanol exists in a balanced tautomerization between azo / hydrazone forms. For further study on the effect of polarity of solvent (DMF), a more polar solvent was selected and the spectra were measured in it. Herein, the stability of hydrazone form in dyes $5 \mathbf{e}$ and $\mathbf{5 f}$ was increased due to high basicity and high relative permittivity of this solvent [80]. Therefore, shoulders have changed to distinct peaks (Fig. 6C). Although the azo form in dyes 5e and $\mathbf{5 f}$ in DMF is still the dominant form, the hydrazone form could become more abundant to reach an equilibrium with the azo form where it is hardly possible through utilization of methanol and dichloromethane solvents. However, the main peak of $\mathbf{5 g}$ has shifted to a higher wavelength $\left(\lambda_{\max }=633 \mathrm{~nm}\right)$ and a shoulder protruded lower wavelength where the azo form of $\mathbf{5 e}$ and $\mathbf{5 f}$ exist. Therefore, the hydrazone form is the dominant form of $\mathbf{5 g}$ exists in DMF (Fig. 6C). A similar result also obtained for $\mathbf{4 e ,} \mathbf{4 f}$ and $\mathbf{4 g}$, however for $\mathbf{4 e}$, the stability of hydrazone form is lower than 5e due to the lack of nitrogen atom of the quinoline group responsible of strengthening of $\mathrm{H}$-bond. The stabilization of hydrazone form in dyes 4 through intramolecular $\mathrm{H}$-bond has already been observed when $-\mathrm{COOH}$ was recruited as substituent at the orthoand para- position of the phenyl ring [49]. These results for paranitro are consistent with those for para-COOH azo dyes, however the absorption spectra of ortho-nitro shows two maximums in DMF evidencing the existence of both tautomeric forms while it just exhibit one maximum peak for the ortho- $\mathrm{COOH}$ derivative. Therefore, it could be concluded that the bifurcated H-bond and the stability of hydrazone form depends on the nature of the group in orthoposition.

The UV-visible spectra of dyes $\mathbf{5 d}$ and $\mathbf{4 d}$ and their para-nitro analogous (5g and $\mathbf{4 g}$ ) indicate for the domination of the azo form in dichloromethane solvent. The influence of nitro group in both $\mathbf{5 g}$ and $\mathbf{4 g}$ creates a bathochromic shift about $\Delta \lambda=30 \pm 3 \mathrm{~nm}$ than unsubstituted analogous (5d and $\mathbf{4 d}$ ) (Fig. 7A). In DMF, dye $\mathbf{5 g}$ is dominantly present in the hydrazone form with a bathochromic shift $\left(\Delta \lambda_{3}=249 \mathrm{~nm}\right)$ in comparison with 5d that dominantly available in the azo form (peak 4 in Fig. 7B). Dye $\mathbf{4 g}$ also in DMF shows a similar spectrum with hydrazone form more present with a bathochromic shift $\left(\Delta \lambda_{2}=156 \mathrm{~nm}\right)$ compared to $4 d$. Here the point is that $\mathbf{4 d}$ also shows a hydrazone form being present unlike 5d (4d shows hydrazone form as dominant tautomer, while the 5d shows dominantly azo form with $\Delta \lambda_{1}=94 \mathrm{~nm}$ ). The smaller peaks 1,2 and also shoulder 3 attributes to the azo form of $\mathbf{5 g}, \mathbf{4 g}$ and 4d (Fig. 7B).

Compound $\mathbf{5 i}$ is the only dye that has similar behavior of $\mathbf{5 g}$ in DMF exhibiting a mixture of both tautomers with hydrazone-form being dominantly available. However, the tautomerization behavior in its 8HQ analogous (4i) is completely reversed where the azoform is the major form. Their spectra are almost symmetric to each other (Fig. 8). 


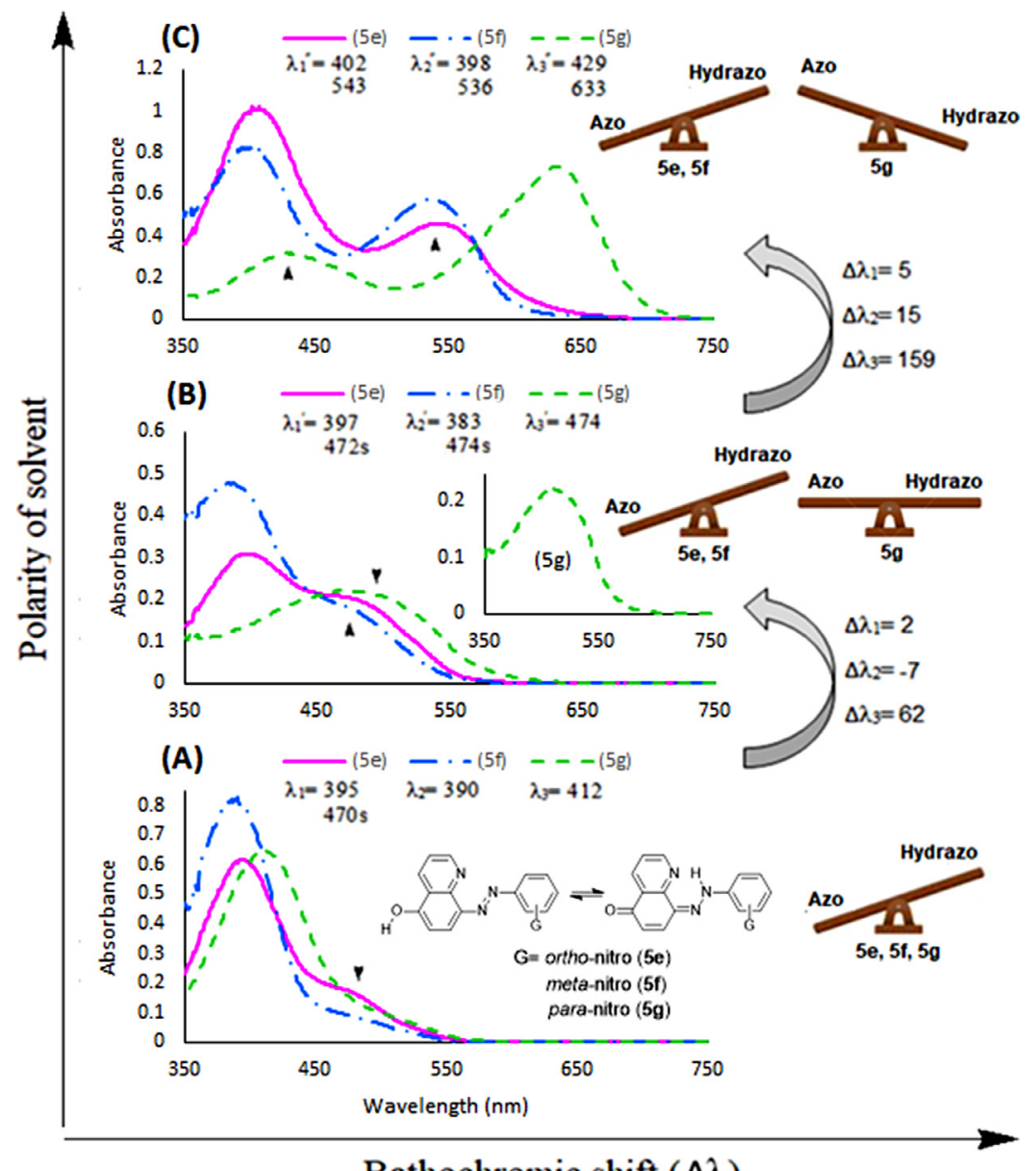

Bathochromic shift $(\Delta \lambda)$

Fig. 6. Absorption spectra of azo dyes $\mathbf{5 e}, \mathbf{5 f}$ and $\mathbf{5 g}$ in DCM (A), in methanol (B) and in DMF (C).
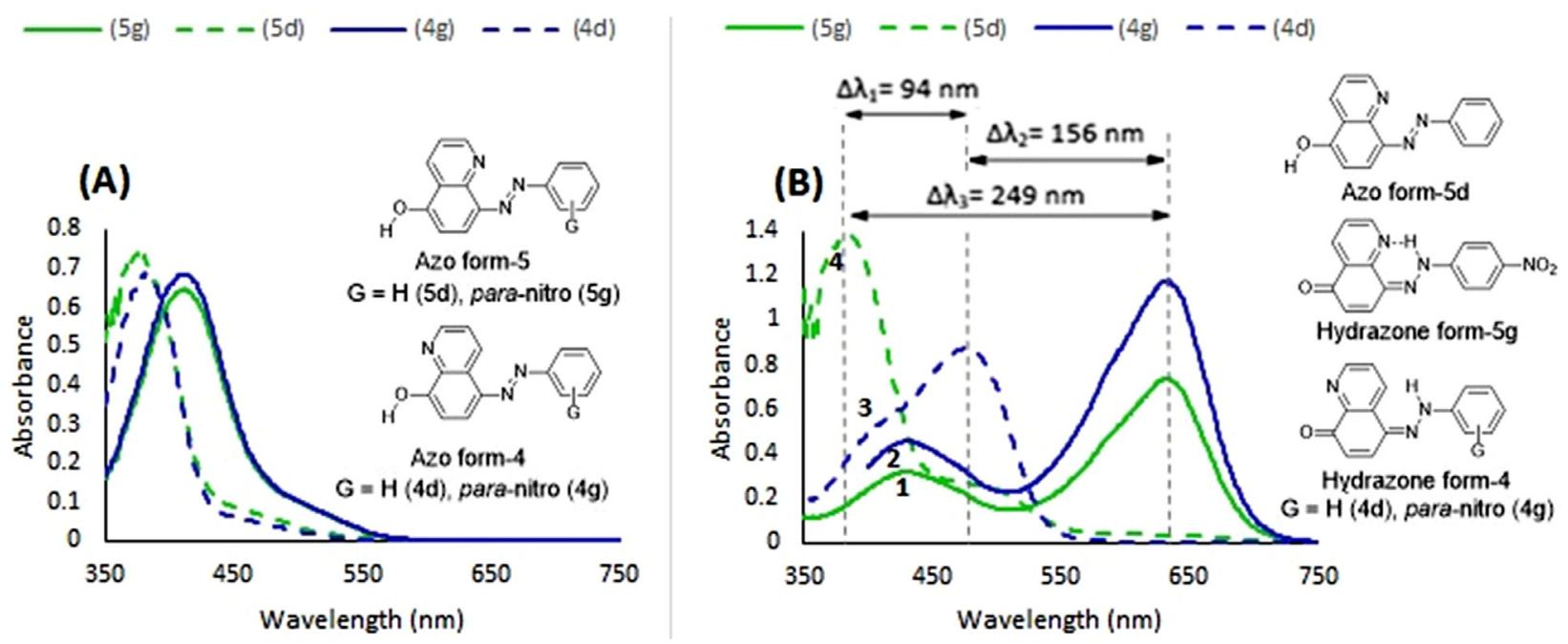

Fig. 7. Comparison of the absorption spectra of dyes $\mathbf{5 d}$ and $\mathbf{5 g}$ with $\mathbf{4 d}$ and $\mathbf{4 g}$ in DCM (A) and DMF (B).

Introduction of an electron donor group like methoxyl (4a and $\mathbf{5 a}$ ) and methyl (4b and $\mathbf{5 b}$ ) in the para-position of the phenyl ring (unlike in ortho-position [81]) does not have a specific effect on the UV-visible spectrum in these dyes, compared to the other substituents, whereas the addition of the stronger electron donor methoxyl group in dyes $\mathbf{4 a}$ and $\mathbf{5 a}$ results in a less stabilization of the hydrazone-form than the methyl group in dyes $\mathbf{4 b}$ and $\mathbf{5 b}$. All the UV-visible spectra of the synthesized compounds studied in three different solvents of dichloromethane, methanol and DMF were presented in the Figs. S94-S99.

\subsection{Substituents effect on the absorption spectra of the dyes}

The extended conjugated system within these azo dyes allows the absorption of visible light. Therefore, the solutions of these compounds in different solvents exhibit yellow, orange and red col- 


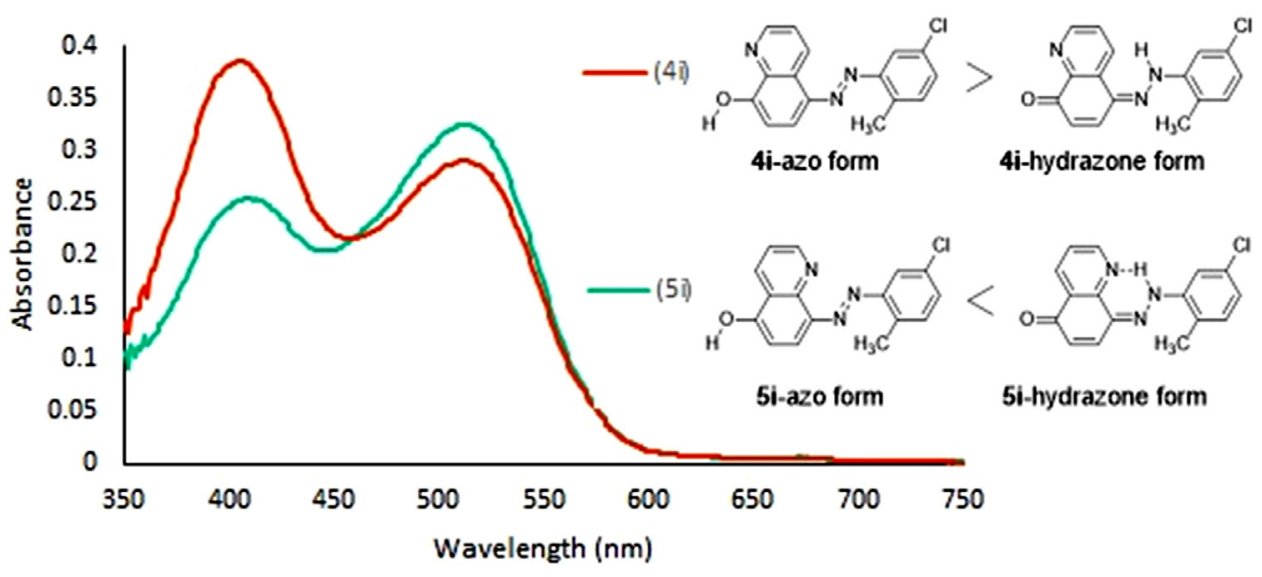

Fig. 8. Comparison of the absorption spectra of $\mathbf{4 i}$ and $\mathbf{5 i}$ in DMF.

ors, which indicates their absorption of the light in the violet, blue and green part of the spectrum, respectively. Moreover, these results indicate that the azo dyes tend to absorb in the near-UV region of the visible right rather that in the near-IR region of light.

The role of electronic effects of substituents on the $\lambda_{\max }$ is a well-known phenomenon in azo dye compounds $[49,75,76]$. A bathochromic shift is expected when azo dyes are functionalized with stronger electron-acceptor substituents (Table 2). The introduction of the nitro group as an electron-acceptor substituent in various position (ortho-, meta-, para-) of the phenyl ring generates bathochromic shifts compared to azo derivatives which are not functionalized with the nitro group (4d or $\mathbf{5 d}$ ). Therefore, a minimum bathochromic shift was observed for $\mathbf{4 f}$ in dichloromethane $(\Delta \lambda=9 \mathrm{~nm})$ whereas a maximum bathochromic shift value was noticed for $\mathbf{5 g}$ in DMF $(\Delta \lambda=249 \mathrm{~nm})$. Furthermore, the bathochromic shift increases with the existence of a nitro group at ortho- and para-position (compared to meta-) due to the resonance effect. Similarly, introduction of an electron-donating group (for example the methoxyl group in $\mathbf{4 a}$ or $\mathbf{5 a}$, and the methyl group in $\mathbf{4 b}$ or $\mathbf{5 b}$ ) at the para-position of phenyl ring causes a bathochromic shift compared to unsubstituted analogous (4d or 5d): a minimum bathochromic shift was observed for $\mathbf{4 b}$ in dichloromethane $(\Delta \lambda=1 \mathrm{~nm})$ whereas a maximum bathochromic shift value was noticed for $\mathbf{5 b}(\Delta \lambda=19 \mathrm{~nm})$. Compounds $\mathbf{4 a}$ and 4b show also a hypsochromic shift of about $\Delta \lambda=-80 \mathrm{~nm}$ and $\Delta \lambda=-89 \mathrm{~nm}$, respectively. These results are fairly matching with those reported for 5-phenylazo-8-hydroxyquinoline dyes [75,76]. It is well known that aryl azo dyes substituted with electron-acceptor groups will exhibit higher bathochromic shifts compared to the corresponding azo dyes functionalized with electron-donor groups. The introduction of halogen substituents to the phenyl ring (4c, $\mathbf{5 c}, \mathbf{4 h}, \mathbf{5 h}, \mathbf{4 i}$ and $\mathbf{5 i}$ ) results in the appearance of an intermediate bathochromic shift (more than electron-donating groups (EDG) and less than electron-accepting groups (EAG) following the order EAG > halogen > EDG). The existence of two chlorine atoms on the phenyl ring in dye $\mathbf{5 h}$ causes a bathochromic shift compared to $\mathbf{5 c}$ and $\mathbf{5 i}$ which are not functionalized with halogen groups. Furthermore, among dyes $\mathbf{4 c}$, $\mathbf{4 h}$ and $\mathbf{4 i}$, which have hypsochromic shift relative to $\mathbf{4 d}$, compound $\mathbf{4 h}$ shows a small shift. A similar hypsochromic shifts were noticed in azo dyes with chlorine in metaposition [82], nitro-substituted (ortho- or para-) [83] and crowding substituents at the phenyl ring [84]. However, it could be concluded that bathochromic or hypsochromic effects caused by the addition of a substituent is highly dependent on the applied solvent [85].

In this section, the colors of solutions for the studied dyes under room temperature are depicted in the Fig. 9A-C. Almost all
Table 3

Spectrokinetic properties under continuous visible irradiation: maximum wavelength of absorption $\left(\lambda_{\max }\right), Z / E$ isomerization rate constant $\left(k_{\Delta}\right)$ and half-life $\left(\mathrm{t}_{1 / 2}\right)$ of azo dyes (4a-i) and (5ai).

\begin{tabular}{llllll}
\hline Entry & Dye & $\mathrm{G}$ & $\lambda_{\max }$ & $k_{\Delta}\left(\mathrm{min}^{-1}\right)$ & $\mathrm{t}_{1 / 2}(\mathrm{~s})$ \\
\hline 1 & $\mathbf{4 a}$ & $p-\mathrm{OMe}$ & 387 & 0.33 & 126 \\
2 & $\mathbf{4 b}$ & $p-\mathrm{Me}$ & 383 & 0.242 & 171 \\
3 & $\mathbf{4 c}$ & $5-\mathrm{Cl}-2-\mathrm{Me}$ & 391 & 5.26 & 7.3 \\
4 & $\mathbf{4 d}$ & $\mathrm{H}$ & 382 & 0.286 & 145 \\
5 & $\mathbf{4 e}$ & $0-\mathrm{NO}_{2}$ & 395 & $*$ & $*$ \\
6 & $\mathbf{4 f}$ & $m-\mathrm{NO}_{2}$ & 386 & $*$ & $*$ \\
7 & $\mathbf{4 g}$ & $p-\mathrm{NO}_{2}$ & 415 & $*$ & $*$ \\
8 & $\mathbf{4 h}$ & $2,5-\mathrm{di}-\mathrm{Cl}$ & 399 & 3.17 & 13.1 \\
9 & $\mathbf{4 i}$ & $3-\mathrm{Cl}-2-\mathrm{Me}$ & 388 & 0.63 & 66 \\
10 & $\mathbf{5 a}$ & $p-\mathrm{OMe}$ & 393 & 2.22 & 18.7 \\
11 & $\mathbf{5 b}$ & $p-\mathrm{Me}_{10}$ & 381 & 3.89 & 10.7 \\
12 & $\mathbf{5 c}$ & $5-\mathrm{Cl}-2-\mathrm{Me}$ & 392 & 0.85 & 48.9 \\
13 & $\mathbf{5 d}$ & $\mathrm{H}$ & 382 & 4.97 & 8.4 \\
14 & $\mathbf{5 e}$ & $0-\mathrm{NO}_{2}$ & 395 & $*$ & $*$ \\
15 & $\mathbf{5 f}$ & $m-\mathrm{NO}_{2}$ & 393 & 7.69 & 5.4 \\
16 & $\mathbf{5 g}$ & $p-\mathrm{NO}_{2}$ & 420 & $*$ & $*$ \\
17 & $\mathbf{5 h}$ & $2,5-\mathrm{di}-\mathrm{Cl}$ & 400 & 2.35 & 17.7 \\
18 & $\mathbf{5 i}$ & $3-\mathrm{Cl}_{-}-\mathrm{Me}$ & 387 & 4.50 & 9.24 \\
\hline
\end{tabular}

* No any spectral change is noticeable upon irradiation for several minutes which suggests a very fast switching between the $E$ and $Z$ forms.

dyes in dichloromethane exhibit in the same color with an exception for nitro-substituted derivatives, which show a shade of orange (Fig. 9A). Obvious color changes were observed by naked eye upon changing the solvent to methanol (Fig. 9B), but the most significant color change was noticed using as solvent DMF. Fig. $9 \mathrm{C}$ shows that all dyes exhibit a bathochromic shift in the UV-visible using an aprotic polar solvent such as DMF. Indeed, Fig. 9A-C provides a straightforward evidence of the solvatochromic properties of the synthesized dyes.

\subsection{Photochromic properties}

The photochromic behavior of the azo dyes $\mathbf{4 a - i}$, 5a-i were studied in acetone $\left(10^{-5} \mathrm{M}\right)$ solutions. The UV-Visible spectra of the samples were measured while irradiating with UV-vis light (250-700 nm) from a $150 \mathrm{~W}$ ozone free xenon lamp, equipped with a water filter at $20{ }^{\circ} \mathrm{C}$, (Table 3 ). The change in the visible spectra of dye $\mathbf{5 d}$ is depicted in Fig. 10A, as an example. The coloration rates were effectively independent on the nature of substituents present on the benzene ring. When the irradiation stopped the absorption of the azo E-isomer increased again. This procedure was repeated several times, and this behavior was fully 
(A)

(B)

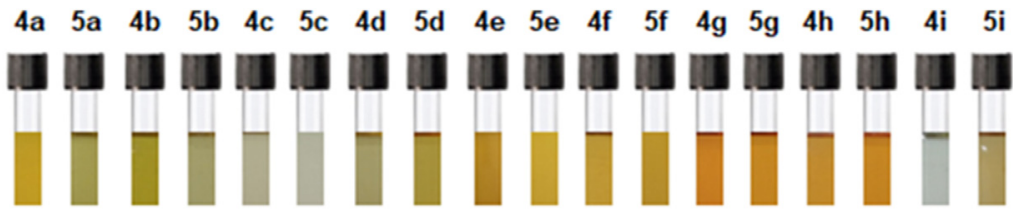

(C)

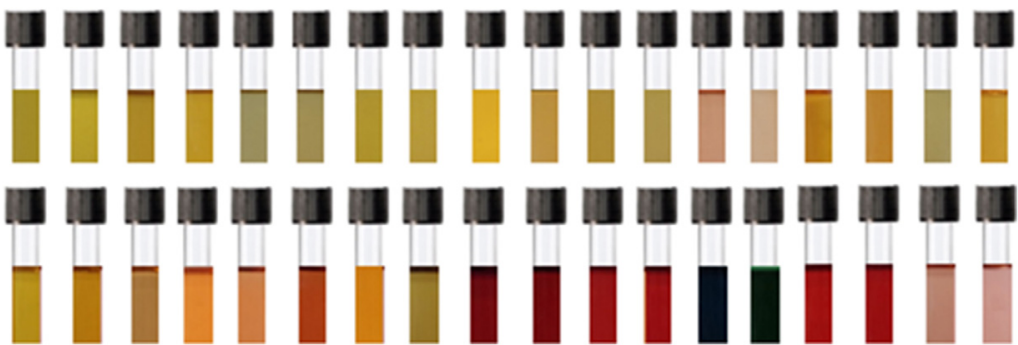

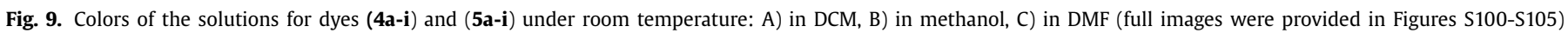
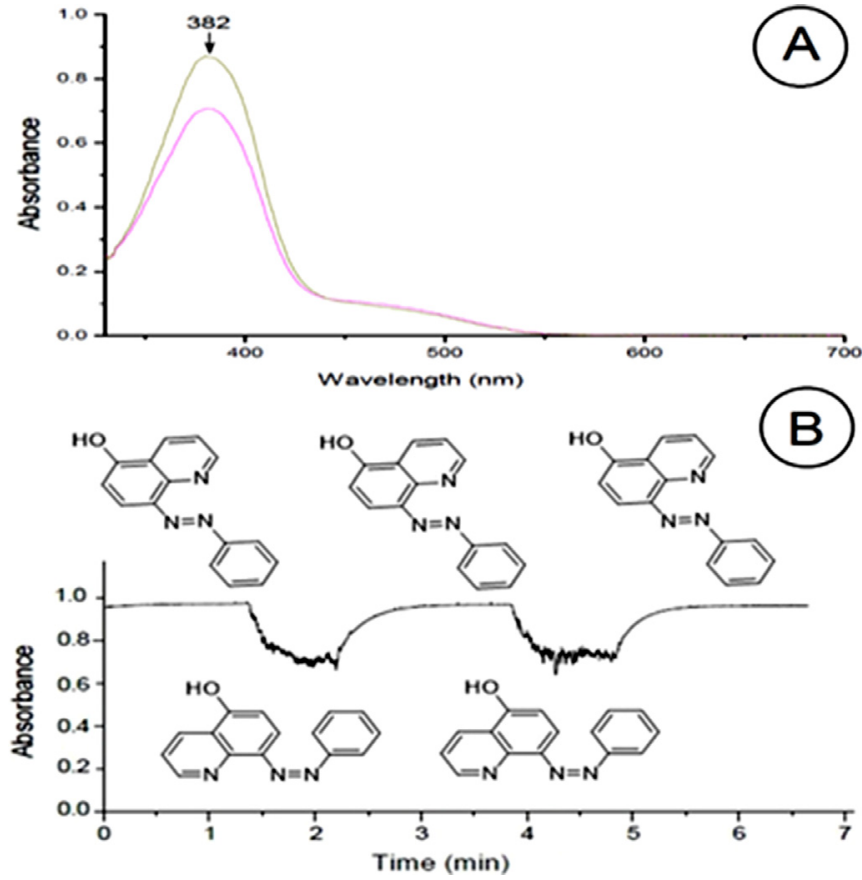

Fig. 10. Absorption spectra of dye $\mathbf{5 d}$ under visible irradiation and in a dark condition (A) and visible irradiation/dark cycles for dye $\mathbf{5 d}$ (B).

reproducible indicating that there is no degradation observed under these limited experimental conditions. The kinetics of the coloration and discoloration process of dye $\mathbf{5 d}$ are shown in Fig. 10B.

The irradiation of azo dyes $\mathbf{4 a - i}$ and $\mathbf{5 a}-\mathbf{i}$ let to a fast and significant drop in the absorption at $\lambda_{\max }$ (around $380-400 \mathrm{~nm}$ ) due to the partial conversion of the $E$-isomer into $Z$-isomer, which absorbs below $350 \mathrm{~nm}$.

The novel azo dyes 8-(aryldiazenyl)quinolin-5-ol (5a-i) were reported to have shorter half-life values (5.4-48.9 s) and larger absorption wavelength range $(381-420 \mathrm{~nm})$ as compared with the azo dyes 5-(aryldiazentl)quinolin-8-ol (4a-i), showing the better prospect of the former in the application for fast molecular photoswitches. The kinetics of the thermal $Z / E$ isomerization (coloration, in dark condition and at $20{ }^{\circ} \mathrm{C}$ ) was slower than the $E / Z$ isomerization but also mono-exponential which can be considered as pseudo first order reactions. The derived pseudo first order kinetics which were presented by Arya et al [86]. The photochemical isomerization of azo dyes involves three reactions which occur at the same time upon the irradiation of UV-Vis-light: (i.) $E / Z$ photoisomerization, (ii.) $Z / E$ photoisomerization and (iii.) $Z / E$ thermal isomerization (Fig. 10B) [87]. A continuous irradiation will result in an $E / Z$ photostationary equilibrium state of azo dye. Upon the removal of irradiation (dark cycle), Z/E thermal isomerization will occur to form the thermodynamically more stable $E$ isomer. Though the kinetics of $E / Z$ and $Z / E$ isomerization had mono-exponential trend, various studies were done to show that they do not proceed in the manner of an elementary reaction step. Spectroscopic studies have reported of the formation of singlet-triplet transition state during azobenzene photochemical isomerization. Such formation involved the excitation of ground states to the $S_{1}\left(n \rightarrow \pi^{*}\right)$ and the $S_{2}$ $\left(\pi \rightarrow \pi^{*}\right)$ states via inversion and rotation mechanisms respectively [88]. The relaxation mechanism of these excited states also displayed wavelength dependence and do not obey Kasha's rule, causing a change in quantum yield without any detectable side reactions during isomerization.

The UV/Vis absorption spectra of all dyes except $4 \mathbf{e}, \mathbf{4 g}, \mathbf{5 e}$ and 5g derivatives showed bathochromic shifts during $E / Z$ isomerization and hypsochromic shifts during $Z / E$ isomerization. The nitro substituted dyes do not show any spectral change upon irradiation for several minutes suggesting a very fast switching between the $Z$ and $E$ forms. The change in $Z / E$ isomerization rate constants of dye $\mathbf{4}$ and $\mathbf{5}$ were also noted when the type and the position of substituent are changed. Here, the comparisons of rate constants were made with reference to the rate constant of the unsubstituted dye $(G=H)$. With the use of electron donating or withdrawing substituent, the rate constants were slightly altered which indicate the polar (inductive and resonance) effects on the Z/E isomerization. The rate constant was the most affected when a substituent of high steric factor such as chlorine was introduced. The placement of these substituents at ortho $(2,6)$ and para $(3,5)$ positions had the most significant steric effect in affect the isomerization rate constant. The polar and steric effects of substituents on the Z/E isomerization reactivity were analyzed using the Taft equation:

$\log \left(\frac{k_{\Delta, G}}{k_{\Delta, H}}\right)=\rho^{*} \sigma^{*}+\delta E_{S}$

where $k_{\Delta, G}$ is the $Z / E$ isomerization constant for $G$-substituted dye, $k_{\Delta, H}$ is the $Z / E$ isomerization constant for unsubstituted dye, $\rho^{*}$ is the sensitivity factor of $Z / E$ isomerization to polar effect, $\sigma^{*}$ is the polar substituent constant, $\delta$ is the sensitivity factor of $Z / E$ isomerization to steric effect and $E_{S}$ is the steric substituent constant. The values of $\sigma^{*}$ and $E_{S}$ can be obtained from the work by Hansch et al [89]. Based on regression analysis, the values of $\rho^{*}$ and $\delta$ for Z/E isomerization were -0.462 and -0.286 for dye 4 and 1.446 and -0.286 for dye $\mathbf{5}$. 
The negative $\delta$ values for the $Z / E$ isomerization of both dyes indicate that the increase in steric bulk of substituent will accelerate the $Z / E$ isomerization rate and favor the formation of the more stable $E$ isomer as $E$ isomer experiences lesser steric hindrance. As dye molecule undergoes $Z / E$ isomerization with the attempt of lessening steric hindrance to achieve better stability, one would also expect that the $Z / E$ isomerization to have a negative entropy of activation as it forms a transition state of lower steric effect. The $\rho^{*}$ sensitivity factors were very much different for the $Z / E$ isomerization of both dyes. For dye $\mathbf{4}$, a negative $\rho^{*}$ denotes that its $Z / E$ isomerization is accelerated by electron donating effect. This effect was noted in the aforementioned discussion to further stabilize the extended $\pi$-conjugation system in $E$ isomer, thus favoring the formation of $E$ isomer. However, this polar effect is not as significant as compared with the polar effect in dye $\mathbf{5}$ as the former also strengthened the $\pi$-bond character of azo group in $Z$ isomer. For dye $\mathbf{5}$, a positive $\rho^{*}$ denotes that its $Z / E$ isomerization is accelerated by electron withdrawing effect. In dye $\mathbf{5}$, the nitrogen position of another pyridine group is facing the conjugated azo group (Scheme 1) to form an azo-hydrazone tautomeric equilibrium. In hydrazone-form, the $\pi$-bond character of azo group is lesser and could be further weakened using an electron donating substituent, thus enabling easier $Z / E$ isomerization. The position of electron donating substituent at position 2 (ortho-) and 3 (meta-) also further stabilizes the $E$ isomer by enabling the formation of bifurcated intramolecular hydrogen bonds (Scheme 3).

\section{Conclusion}

Novel substituted 8-(aryldiazenyl)quinolin-5-ol azo dyes were synthesized and investigated in this work. Spectroscopic studies confirmed the tautomerism of these dyes in the form of azo/hydrazone equilibrium. For nitro substituted azo dyes, bifurcated intramolecular hydrogen bonds were formed which subsequently stabilize the hydrazone tautomer. The effect of the substituents of different electronic nature and hydrogen bond acceptor strengths on the azo/hydrazone and the $E / Z$ equilibria were also investigated. These equilibrium were reported to be mainly affected by steric effect of substituent and field effects due to hydrogen bonding and the contribution of substituent to the extended $\pi$ conjugation azo system. Photochemical isomerization kinetics also revealed that the novel substituted-azo dyes have higher $Z / E$ thermal isomerization rates and have larger absorbance wavelength range than their 8-hydroxyquinoline analogs, making them potential molecular switches. These insights would serve as the bases for further studies on the photochromic performance of other substituted 5-hydroxyquinoline dyes in near future.

\section{Declaration of Competing Interest}

The authors whose names are listed immediately below certify that they have NO affiliations with or involvement in any organization or entity with any financial interest (such as honoraria; educational grants; participation in speakers' bureaus; membership, employment, consultancies, stock ownership, or other equity interest; and expert testimony or patent-licensing arrangements), or nonfinancial interest (such as personal or professional relationships, affiliations, knowledge or beliefs) in the subject matter or materials discussed in this manuscript.

\section{CRediT authorship contribution statement}

Hamid Rashidnejad: Methodology, Investigation, Writing original draft. Mohammad Ramezanitaghartapeh: Methodology, Investigation, Writing - original draft. Nader Noroozi Pesyan: Data curation. Peter J. Mahon: Data curation. M. Manuela M. Raposo:
Writing - review \& editing. Paulo J. Coelho: Writing - review \& editing. Andrew Ng Kay Lup: Writing - review \& editing. Alireza Soltani: Methodology, Investigation, Writing - original draft.

\section{Acknowledgements}

Hamid Rashidnejad and Dr. Nader Noroozi Pesyan want to thank Urmia University's higher education department for provided facilities. We thank the clinical Research Development Unit (CRDU), Sayad Shirazi Hospital, Golestan University of Medical Sciences, Gorgan, Iran. Mohammad Ramezani Taghartapeh acknowledges the SUPRA scholarship provided by Swinburne University of Technology. M.M.M. Raposo would like to gratefully acknowledge the financial support from Foundation for Science and Technology (FCT), to Centro de Química, CQUM, under the project UID/QUI/00686/2020.

\section{Supplementary materials}

Supplementary material associated with this article can be found, in the online version, at doi:10.1016/j.molstruc.2020.129323.

\section{References}

[1] M. Gsänger, D. Bialas, L. Huang, M. Stolte, F. Würthner, Adv. Mater. 28 (2016) 3615-3645, doi:10.1002/adma.201505440.

[2] R.M. El-Shishtawy, F.A.M. Al-Zahrani, S.M. Afzal, M.A.N. Razvi, Z.M. Al-amshany, A.H. Bakry, A.M. Asiri, RSC Adv. 6 (2016) 91546-91556, 10.1039/C6RA13839J.

[3] W. Mehl, Reprography process: copying with sublimable dyes, US4134676A, 1977.

[4] R.M. El-Shishtawy, Int. J. Photoenerg. (2009) 1-21 ID434897, doi:10.1155/2009/ 434897.

[5] M.J. Hansen, M.M. Lerch, W. Szymanski, B.L. Feringa, Angew. Chem. Int Ed. 55 (2016) 13514-13518, doi:10.1002/anie.201607529.

[6] C. Poloni, W. Szymanski, L. Hou, W.R. Browne, B.L. Feringa, Chem. Eur. J. 20 (2014) 946-951, doi:10.1002/chem.201304129.

[7] W. Szymanski, B. Wu, C. Poloni, D.B. Janssen, B.L. Feringa, Angew. Chem. Int Ed. 52 (2013) 2068-2072, doi:10.1002/anie.201208596.

[8] K. Hunger, Industrial Dyes: Chemistry, Properties, Applications, Wiley-VCH Verlag GmbH\& Co. KGaA, Weinheim, 2003 ISBN: 978-3-527-30426-4.

[9] P. Hyeyoung, K. Eung-Ryul, K.D. Jin, L. Haiwon, Bull. Chem. Soc. Jpn. 75 (2002) 2067-2070, doi:10.1246/bcsj.75.2067.

[10] T. Gao, Y. Xue, Z. Zhang, W. Que, Opt. Express. 26 (2018) 4309-4317, doi:10. 1364/OE.26.004309.

[11] E. Anger, S.P. Fletcher, Eur. J. Org. Chem. 17 (2015) 3651-3655, doi:10.1002/ ejoc.201500485.

[12] S. Samanta, A.A. Beharry, O. Sadovski, T.M. McCormick, A. Babalhavaeji, V. Tropepe, G.A. Woolley, J. Am. Chem. Soc. 135 (2013) 9777-9784, doi:10.1021/ ja402220t.

[13] Z.V. Soreño, J.M.C. Puguan, H. Kim, Mater. Chem. Phys. 240 (2020) 122297122304, doi:10.1016/j.matchemphys.2019.122297.

[14] A. Saeed, Gh. Shabir, J. Fluoresc. 24 (2014) 1337-1345, doi:10.1007/ s10895-014-1420-1.

[15] Y.A. Gromova, A.O. Orlova, V.G. Maslov, A.V. Fedorov, A.V. Baranov, Nanoscale. Res. Lett. 8 (2013) 452-457, doi:10.1186/1556-276X-8-452.

[16] G.R. Ferreira, B.L. Marcial, H.C. Garcia, F.R.L. Faulstich, H.F. Dos Santos, L.F.C. de Oliveira, Supramol. Chem. 27 (2015) 13-20, doi:10.1080/10610278. 2014.899598.

[17] E. Schab-Balcerzak, J. Konieczkowska, M. Siwy, A. Sobolewska, M. Wojtowicz, M. Wiacek, Opt. Mater. 36 (2014) 892-902, doi:10.1016/j.optmat.2013.12.017.

[18] A.S. Matharu, Sh Jeeva, P.R. Huddleston, P.S. Ramanujam, J. Mater. Chem. 17 (2007) 4477-4482, doi:10.1039/B705648F.

[19] H. Dinçalp, F. Toker, I. Durucasu, N. Avcibasi, S. Icli, Dyes Pigment 75 (2007) 11-24, doi:10.1016/j.dyepig.2006.05.015.

[20] S. Benkhaya, S. M'rabet, A.El Harfi, Heliyon 6 (2020) e03271, doi:10.1016/j. heliyon.2020.e03271.

[21] J.O. Otutu, E. Osabohein, Asian. J. Mater. Sci. 5 (2013) 1-8, doi:10.3923/ajmskr. 2013.1.8.

[22] N.M. Mallikarjuna, J. Keshavayya, J. King Saud Univ. Sci. 32 (2020) 251-259, doi:10.1016/j.jksus.2018.04.033.

[23] K. Golka, S. Kopps, Z.W. Myslak, Toxicol. Lett. 151 (2004) 203-210, doi:10.1016/ j.toxlet.2003.11.016.

[24] J. Isaad, A. Perwuelz, Tetrahedron. Lett. 51 (2010) 5810-5814, doi:10.1016/j. tetlet.2010.08.098.

[25] M. Imran, B. Shaharoona, D.E. Crowely, A. Khalid, S. Hussain, M. Arshad, Ecotoxicol. Environ. Saf. 120 (2015) 163-168, doi:10.1016/j.ecoenv.2015.06.004.

[26] A. Vig, K. Sirbiladze, H.J. Nagy, P. Aranyosi, I. Rusznák, P. Sallay, Dyes Pigment 72 (2007) 16-22, doi:10.1016/j.dyepig.2005.07.010.

[27] A.F. Shoair, A.A. El-Bindary, A.Z. El-Sonbati, R.M. Younes, Spectrochim. Acta A 57 (2001) 1683-1691, doi:10.1016/S1386-1425(01)00398-5. 
[28] M. Ramadan, A. Essam Kh, F Kh. Ahmad, Bull. Chem. Soc. Jpn. 66 (1993) 29362940, doi:10.1246/bcsj.66.2936.

[29] L.E. da Silva, C.R. Andrighetti-fröhner, R.J. Nunes, C.M.O. Simõnes, S. Foro, Acta. Crystallogr E. E62 (2006) o2104-02105, doi:10.1107/S1600536806015017.

[30] M.La Deda, A. Grisolia, I. Aiello, A. Crispini, M. Ghedini, S. Belviso, M. Amati, F. Lelj, Dalton Trans. (2004) 2424-2431, doi:10.1039/B404814H.

[31] A.S.A. Zidan, J. Therm. Anal. Calorim. 68 (2002) 1045-1059, doi:10.1023/A: 1016167311977.

[32] J. Xie, L. Fan, J. Su, H. Tian, Dyes Pigment 59 (2003) 153-162, doi:10.1016/ S0143-7208(03)00106-2.

[33] B.K. Deb, A.K. Ghosh, Can. J. Chem. 65 (1987) 1241-1246, doi:10.1139/v87-210.

[34] Y.P. Kovtun, Y.O. Prostota, A.L. Tolmachev, Dyes Pigment 58 (2005) 83-91, doi:10.1016/S0143-7208(03)00038-X.

[35] H. Zollinger, Color Chemistry, VCH Publishers, Inc, New York, 1991 chapter 7, doi: $10.1002 /$ col.5080130314.

[36] H. Bouas-Laurent, H. Dürr, Organic photochromism (IUPAC Technical Reports), Pure Appl. Chem. 73 (2001) 639-665, doi:10.1351/pac200173040639.

[37] P.J. Coelho, L.M. Carvalho, J.C.V.P. Moura, M.M.M. Raposo, Dyes. Pigm. 82 (2009) 130-133, doi:10.1016/j.dyepig.2008.12.005.

[38] P.J. Coelho, M.C.R. Castro, S.S.M. Fernandes, A.M.C. Fonseca, M.M.M. Raposo, Tetrahedron. Lett. 53 (2012) 4502-4506, doi:10.1016/j.tetlet.2012.05.166.

[39] I.S. Ahmad, Instrum. Sci. Technol. 33 (2005) 33-45, doi:10.1081/CI-200040841.

[40] H. Shaki, K. Gharanjig, A. Khosravi, Biotechnol. Prog. 31 (2015) 1086-1095, doi:10.1002/btpr.2107.

[41] T.S.B. Baul, A. Mizar, X. Song, G. Eng, R. Jirásko, M. Holčapek, R. Willem, M. Biesemans, I. Verbruggen, R. Butcher, J. Organomet. Chem. 691 (2006) 2605-2613, doi:10.1016/j.jorganchem.2006.01.065.

[42] A. Ghanadzadeh Gilani, M. Moghadam, M.S. Zakerhamidi, E. Moradi, Dyes Pigment 92 (2012) 1320-1330, doi:10.1016/j.dyepig.2011.09.021.

[43] Z. Seferoğlu, N. Ertan, Heteroat. Chem. 18 (2007) 622-630, doi:10.1002/hc, 20361.

[44] Z. Seferoğlu, N. Ertan, Russ. J. Org. Chem. 43 (2007) 1035-1041, doi:10.1134/ S1070428007070160.

[45] A. Saylam, Z. Seferoğlu, N. Ertan, Russ. J. Org. Chem. 44 (2008) 587-594, doi:10.1134/S1070428008040209.

[46] Z. Seferoğlu, N. Ertan, T. Hökelek, E. Şahin, Dyes Pigment 77 (2008) 614-625, doi:10.1016/j.dyepig.2007.09.001.

[47] Z. Seferoğlu, N. Ertan, G. Kickelbick, T. Hökelek, Dyes Pigment 82 (2009) 20-25, doi:10.1016/j.dyepig.2008.10.020.

[48] A. Saylam, Z. Seferoğlu, N. Ertan, Dyes Pigment 76 (2008) 470-476, doi:10. 1016/j.dyepig.2006.10.005.

[49] A. Saylam, Z. Seferoğlu, N. Ertan, J. Mol. Liq. 195 (2014) 267-276, doi:10.1016/ j.molliq.2014.02.027.

[50] P.J. Coelho, C.M. Sousa, M.C.R. Castro, A.M.C. Fonseca, M.M.M. Raposo, Opt. Mater. 35 (2013) 1167-1172, doi:10.1016/j.optmat.2013.01.007.

[51] T. Asano, H. Furuta, H.J. Hofmann, R. Cimiraglia, Y. Tsuno, M. Fujio, J. Org. Chem. 58 (1993) 4418-4423, doi:10.1021/jo00068a042.

[52] Y-C. Lu, W-G. Diau, H. Rau, J. Phys. Chem A. 109 (2005) 2090-2099, doi:10. 1021/jp044934b.

[53] K. Matczyszyn, W. Bartkowiak, J. Leszczynski, J. Mol. Struct. 565-566 (2001) 53-57, doi:10.1016/S0022-2860(01)00457-4.

[54] P.J. Coelho, M.C.R. Castro, A.M.C. Fonseca, M.M.M. Raposo, Dyes Pigment 92 (2012) 745-748, doi:10.1016/j.dyepig.2011.06.019.

[55] L.L. Norman, C.J. Barrett, J. Phys. Chem B. 106 (2002) 8499-8503, doi:10.1021/ jp013619b.

[56] R.T. Buwalda, J.M. Jonker, J.B.F.N. Engberts, Langmuir 15 (1999) 1083-1089, doi:10.1021/la980824i.

[57] S.K. Yesodha, C.K.S. Pillai, N. Tsutsumi, Prog. Polym. Sci. 29 (2004) 45-74, doi:10.1016/j.progpolymsci.2003.07.002.

[58] A. Natansohn, P. Rochon, Chem. Rev. 102 (2002) 4139-4176, doi:10.1021/ cr970155y.

[59] V. Balzani, A. Credi, M. Venturi, Molecular Devices and Machines: Concepts and Perspectives for the Nonoworld, second ed., Wiley-VCH, Weinheim, 2008 ISBN: 978-3-527-31800-1.
[60] N. Noroozi Pesyan, Magn. Reson. Chem. 49 (2011) 592-599, doi:10.1002/mrc. 2790.

[61] N. Noroozi Pesyan, H. Rashidnejad, Magn. Reson. Chem. 54 (2016) 358-364, doi: $10.1002 /$ mrc.4390.

[62] Kh.S. Shikhaliev, V.V. Didenko, V.A. Voronkova, D.V. Kryl'skii, Russ. Chem. Bull. 58 (2009) 1034-1040, doi:10.1007/s11172-009-0132-1.

[63] N. Noroozi Pesyan, D. Soleimani, N. Hosseini Jazani, Turk. J. Chem. 39 (2015) 998-1011 http://eprints.umsu.ac.ir/471/1/kim-39-5-8-1412-46.pdf.

[64] A. Ghanadzadeh Gilani, E. Moradi, S. Binay, M. Moghadam, Spectrochim. Acta. Part A. 87 (2012) 112-118, doi:10.1016/j.saa.2011.11.020.

[65] M.A. Rauf, S. Hisaindee, N. Saleh, RSC. Adv. 5 (2015) 18097-18110, doi:10.1039/ C4RA16184J.

[66] A.V. Afonin, I.A. Ushakov, A.I. Mikhaleva, B.A. Trofimov, Magn. Reson. Chem. 45 (2007) 220-230, doi:10.1002/mrc.1949.

[67] N. Noroozi Pesyan, Magn. Reson. Chem. 47 (2009) 953-958, doi:10.1002/mrc. 2498.

[68] F.W. Wehrli, T. Wirthlin, Interpretation of Carbon-13 NMR Spectra, Heyden, London, 1976 ISBN: 0471917427, 9780471917427.

[69] M. Saunders, L. Telkowski, M.R. Kates, J. Am. Chem. Soc. 99 (1977) 8070-8071, doi:10.1021/ja00466a060.

[70] J. Reuben, J. Am. Chem. Soc. 108 (1986) 1082-1083, doi:10.1021/ja00265a039.

[71] M. Rimaz, N. Noroozi Pesyan, J. Khalafy, Magn. Reson. Chem. 48 (2010) $276-$ 285, doi:10.1002/mrc.2573.

[72] J. Reuben, J. Am. Chem. Soc. 105 (1983) 371137 -13, doi:10.1021/ja00349a061.

[73] R.A. Newmark, J.R. Hill, J. Magn. Reson. 21 (1976) 1-7, doi:10.1016/ 0022-2364(76)90246-8.

[74] M. Ramezani Taghartapeh, N. Noroozi Pesyan, H. Rashidnejad, H.R. Khavasi, A. Soltani, J. Mol. Struct. 1149 (2017) 862-873, doi:10.1016/j.molstruc.2017.08. 054.

[75] S. Kishimoto, Sh Kitahara, O. Manabe, H. Hiyama, J. Org. Chem. 43 (1978) 3882-3886, doi:10.1021/jo00414a020.

[76] R.L. Reeves, R.S. Kaiser, J. Org. Chem. 35 (1970) 3670-3675, doi:10.1021/ jo00836a017.

[77] W. Kuznik, I.V. Kityk, M.N. Kopylovich, K.T. Mahmudov, K. Ozga, G. Lakshminarayana, A.J.L. Pombeiro, Spectrochim. Acta A 78 (2011) 1287-1294, doi:10. 1016/j.saa.2010.12.080.

[78] F. Karci, A. Demirçali, Dyes Pigment 71 (2006) 97-102, doi:10.1016/j.dyepig. 2005.08.004.

[79] M.S. Yen, I.J. Wang, Dyes Pigment 67 (2005) 183-188, doi:10.1016/j.dyepig. 2004.11.010.

[80] C. Reichardt, T. Welton, Solvents and Solvent Effects in Organic Chemistry, fourth ed., Wiley-VCH Verlag GmBH \& Co. KGaA, 2010 ISBN: 9783527324736, 9783527632220

[81] A. Penchev, N. Gadjev, D. Simov, B. Hadjieva, N. Balabanova, Dyes Pigment 19 (1992) 113-122, doi:10.1016/0143-7208(92)87016-T.

[82] P.W. Vittum, G.H. Brown, J. Am. Chem. Soc. 68 (1946) 2235-2239, doi:10.1021/ ja01215a035.

[83] M. Kuanar, B.K. Mishra, P. Indian, AS-Chem. Sci. 108 (1996) 451-458, doi:10. 1007/BF02869550.

[84] M. Clark, Handbook of Textile and Industrial Dyeing, Principles, Volume 1, Principles, Processes and Types of Dyes, ISBN: 9780857093974, 9780081016510, 9781845696955

[85] G.S. Ušćumlić, D.Ž. Mijin, N.V. Valentic, V.V. Vajs, B.M. Sušić, Chem. Phys. Lett. 397 (2004) 148-153, doi:10.1016/j.cplett.2004.07.057.

[86] P. Arya, J. Jelken, N. Lomadze, S. Santer, M. Bekir, J. Chem. Phys. 152 (10) (2020) 024904(1)-024904, doi:10.1063/1.5135913.

[87] P.J. Coelho, M.C.R. Castro, M.M.M. Raposo, J. Photoch. Photobio A. 259 (2013) 59-65, doi:10.1016/j.jphotochem.2013.03.004.

[88] S. Malkin, E. Fischer, J. Phys. Chem. 68 (1964) 1153-1163, doi:10.1021 j100787a032.

[89] C. Hansch, A. Leo, R.W. Taft, Chem. Rev. 91 (1991) 165-195, doi:10.1021/ cr00002a004. 